\title{
Minhas palavras para Victor Frankenstein acima da aldeia de Chamonix: Performar a fúria transgênera*
}

\author{
My Words to Victor Frankenstein above the Village of Chamounix
}

\section{Susan Stryker}

Escritora, cineasta, teórica e professora de Gênero e Estudos da Mulher na University of Arizona, foi fundadora da Iniciativa de Estudos Transgênero da mesma universidade. Foi professora visitante em diversas universidades, incluindo Harvard e a University of Califórnia, Santa Cruz. É co-fundadora e co-editora da primeira revista acadêmica não médica sobre questões trans, a TSQ: Transgender Studies Quarterly. Este é o primeiro artigo que publicou, no primeiro ano de existência da revista $G L Q$, de estudos gays e lésbicos, 1994. Ganhou vários prêmios por seus filmes, trabalho acadêmico e ativismo.

\section{Tradução:}

\section{Luiza Quental}

É mestra em Comunicação e Cultura pela UFRJ e formada em cinema pela PUC-Rio. Roteirista, escritora e pesquisadora, ela escreveu e dirigiu dois curta-metragens que passaram por diversos festivais nacionais e internacionais. No campo da pesquisa, tem interesse pelas áreas de estudos de ciência, tecnologia e sociedade e humanidades digitais.

Revisão: Liv Sovik

\section{RESUMO}

A metáfora do monstro, frequentemente usada contra pessoas transgêneras, evoca aqui a fúria transgênera diante das interdições que defendem o binarismo sexual. Diversos gêneros textuais e tipos de conhecimento são usados para explorar aspectos da experiência trans.

PALAVRAS-CHAVE: pessoas trans; monstro; autobiografia; psicanálise.

\footnotetext{
* Publicado originalmente como "My Words to Victor Frankenstein Above the Village of Chamounix: Performing Transgender Rage," in GLQ: A Journal of Lesbian and Gay Studies, Volume 1, no. 3, pp. 237-254. Copyright, Duke University Press. All rights reserved. Republished by permission of the copyright holder, Duke University Press. www.dukeupress.edu.
}

Dossiê Feminismos vitais - https://revistaecopos.eco.ufri.br/

ISSN 2175-8689 - v. 24, n. 1, 2021

DOI: 10.29146/ecopos.v24i1.27775 


\section{ABSTRACT}

The metaphor of the monster, often used against transgender people, evokes here transgender fury in the face of the interdictions that defend sexual binarism. Different textual genres and kinds of knowledge are used to explore aspects of trans experience. KEYWORDS: transgender people; monster; autobiography; psychoanalysis.

Submetido em 24 de Maio de 2021 Aceito em 17 de Julho de 2021

\section{Notas introdutórias}

Este trabalho é uma adaptação textual de uma obra performática originalmente apresentada em "Rage Across the Disciplines" [Fúria através das disciplinas] ${ }^{\dagger}$ uma conferência de artes, humanidades e ciências sociais realizada de 10 a 12 de junho de 1993, na Universidade Estadual da Califórnia em San Marcos. A natureza interdisciplinar da conferência, seu tema e a chamada dos organizadores para trabalhos acadêmicos e performances me inspiraram a ser criativa em meu modo de apresentar um tema que naquele momento não saia da minha cabeça. Como membra da Transgender Nation - um grupo de advocacy militantemente queer, de ação direta transexual - eu estava na época envolvida na organização de um protesto na reunião anual de 1993 da Associação Americana de Psiquiatria, em São Francisco. Grande parte da discussão em nossas reuniões de planejamento dizia respeito a como captar as emoções intensas que emanam da experiência transexual - especialmente a fúria - e mobilizá-las para ações políticas efetivas. Fiquei intrigada pela perspectiva de examinar criticamente essa fúria em um ambiente mais acadêmico por meio de uma aplicação idiossincrática do conceito de performatividade de gênero. Minha ideia era conscientemente performar um gênero queer em vez de simplesmente falar sobre ele, assim incorporando e implementando simultaneamente o conceito em discussão. Eu queria que a estrutura formal do trabalho expressasse uma estética transgênera ao

\footnotetext{
† "Rage", em ingles, é o substantivo "fúria", e também um verbo que significa enfurecer-se e, por extensão, expressar ou se movimentar com fúria. Daí "Rage Across the Disciplines" significa "Fúria através das disciplinas", ou a fúria numa visão transdisciplinar e, também, um chamado para se mover com fúria através das disciplinas, tumultuando-as. [N.T.]
}

Dossiê Feminismos vitais - https://revistaecopos.eco.ufri.br/

ISSN 2175-8689 - v. 24, n. 1, 2021

DOI: 10.29146/ecopos.v24i1.27775 
replicar nossas transições abruptas, muitas vezes chocantes entre gêneros, desafiando a classificação genérica com as formas das minhas palavras, assim como minha transexualidade desafia as convenções de gênero legítimo e minha performance na sala de conferências desafiou as fronteiras do discurso acadêmico aceitável. Durante a apresentação, eu fiquei de pé no pódio vestida no estilo drag genderfuck - coturnos, uma calça jeans Levi 501 surrada sobre um body de renda preta, uma camiseta rasgada da Transgender Nation com a gola e as mangas cortadas, um colar com um pingente triangular de quartzo rosa, bijuteria de metal grunge, e um anzol de espadim de quinze centímetros de comprimento pendurado em meu pescoço em um pedaço de corrente de aço inoxidável pesado. Decorei o cenário pendurando minha jaqueta de couro preta sobre minha cadeira na mesa do painel. A jaqueta tinha algemas no ombro esquerdo, anéis das cores do arco-íris nos laços do lado direito e adesivos queer com os as palavras MUDANÇA DE SEXO, SAPATONA, e FODA-SE SUA TRANSFOBIA nas costas.

\section{Monólogo}

O corpo transexual é um corpo não natural. É um produto da ciência médica. É uma construção tecnológica. É carne dilacerada e costurada novamente em uma forma diferente daquela em que nasceu. Nessas circunstâncias, encontro uma profunda afinidade entre mim, como mulher transexual, e o monstro de Frankenstein de Mary Shelley. Como o monstro, demasiadas vezes sou percebida como menos do que totalmente humana devido aos meios de minha encarnação; como o monstro também, minha exclusão da comunidade humana alimenta uma fúria profunda e duradoura em mim, que eu, como o monstro, dirijo contra as condições nas quais preciso lutar para existir.

Não sou a primeira a ligar o monstro de Frankenstein e o corpo transexual. Mary Daly torna a conexão explícita ao discutir a transexualidade em "Boundary Violation and the Frankenstein Phenomenon" [Violação de limites e o fenômeno Frankenstein], no qual ela caracteriza transexuais como os agentes de uma "invasão necrofílica" do espaço feminino (69-72). Janice Raymond, que reconhece Daly como uma influência formadora, 
é menos direta quando diz que "o problema da transexualidade seria melhor resolvido se um comando moral lhe fadasse a desaparecer", mas mesmo assim, nesta declaração ela ecoa os sentimentos de Victor Frankenstein em relação ao monstro: "Vá embora, inseto vil, ou melhor, fique, para que eu possa pisotear você até virar pó. Você me reprova com sua criação" (Raymond 178; Shelley 95). É um lugar-comum da crítica literária notar que o monstro de Frankenstein é o duplo sombrio e romântico do cientista, o Outro estranho que ele constrói e sobre o qual projeta tudo o que não pode aceitar em si mesmo; de fato, Frankenstein chama o monstro de "meu próprio vampiro, meu próprio espírito libertado da sepultura" (Shelley 74). Posso sugerir que Daly, Raymond e outros da mesma laia similarmente constroem a pessoa transexual como seu golem particular? ${ }^{1}$

A atribuição de monstruosidade permanece uma característica palpável da maioria das representações lésbicas e gays da transexualidade, exibindo em detalhes desconcertantes a face ansiosa e medonha do atual fascínio cultural pela transgeneridade. ${ }^{2}$ Devido à transexualidade, mais do que qualquer outra prática ou identidade transgênera, representar a possibilidade de desestabilizar a pressuposição fundacional de gêneros fixos da qual depende uma política de identidade pessoal, pessoas que investiram suas aspirações por justiça social em movimentos identitários dizem coisas sobre nós por puro pânico que, se ditas de outras minorias, seriam impressas apenas nos mais odiosos jornalecos de supremacistas brancos e fascistas cristãos. Para citar extensivamente uma carta ao editor de um popular periódico gay/lésbico de San Francisco:

$\mathrm{Eu}$ considero o transexualismo uma fraude, e os participantes dele ... pervertidos. 0 transexual [alega] que precisa mudar seu corpo para ser o seu "verdadeiro eu". Já que este "verdadeiro eu" requer outra forma física para se manifestar, ele/a deve, portanto, guerrear com a natureza. Não se pode mudar o gênero. 0 que ocorre é um exterior habilmente manipulado: o que foi feito é uma mutação. 0 que existe debaixo da superfície deformada é a mesma pessoa que estava lá antes da deformidade. Pessoas que quebram ou deformam seus corpos [realizam] a farsa doentia de uma abordagem iludida e patriarcal à natureza, alienada do ser verdadeiro.

Dossiê Feminismos vitais - https://revistaecopos.eco.ufri.br/

ISSN 2175-8689 - v. 24, n. 1, 2021

DOI: 10.29146/ecopos.v24i1.27775 
Fazendo referência por nome a uma pessoa em particular, que se identificava como lésbica transexual, que ela havia ouvido falar em um fórum público no Edifício das Mulheres de São Francisco, a autora da carta continuou:

Quando um homem estrogenado e com seios ama uma mulher, isso não é lesbianismo, isso é perversão mutilada. [Este indivíduo] não é uma ameaça para a comunidade lésbica, ele é um ultraje para nós. Ele não é uma lésbica, ele é um homem mutante, uma aberração que se fez sozinha, uma deformidade, um insulto. Ele merece um tapa na cara. Depois disso, ele merece ter seu corpo e mente curados novamente. ${ }^{3}$

Quando seres como esse me dizem que eu guerreio com a natureza, não encontro mais razão para lamentar minha oposição a eles - ou à ordem que afirmam representar do que o monstro de Frankenstein sentiu em sua inimizade para com a raça humana. Eu não caio da graça de sua companhia - eu rujo alegremente para longe dela como uma sapatona do inferno a bordo de um Harley Davidson, vestida de couro e carregando dildos.

A estigmatização fomentada por esse tipo de rotulação pejorativa não é sem consequências. Essas palavras têm o poder de destruir vidas transexuais. Em 5 de janeiro de 1993, uma transexual em situação pré-operatória de 22 anos de Seattle, Filisa Vistima, escreveu em seu diário: “Gostaria de ser anatomicamente 'normal' para poder nadar... Mas não, eu sou uma mutante, o monstro de Frankenstein". Dois meses depois, Filisa Vistima suicidou-se. 0 que a levou a tal desespero foi a exclusão que experimentou na comunidade queer de Seattle, alguns membros da qual se opuseram à participação de Filisa por causa de sua transexualidade - embora ela se identificasse e vivesse como uma mulher bissexual. 0 centro de recursos lésbico onde ela trabalhou como voluntária, fez um levantamento com sua base para decidir se deveria parar de oferecer serviços a transexuais em transição de homem para mulher. Filisa fez a inserção de dados para tabular os resultados da pesquisa; ela não precisava imaginar como as pessoas se sentiam a respeito de seu tipo. A Rede de Mulheres Bissexuais de Seattle (SBWN) anunciou que se admitisse transexuais, a SBWN deixaria de ser uma organização de mulheres. "Tenho certeza", disse uma membra em referência à inclusão de mulheres 
transexuais bissexuais, "que os meninos podem cuidar de si mesmos". Filisa Vistima não era um menino e para ela foi impossível cuidar de si mesma. Mesmo na morte, ela não encontrou apoio da comunidade à qual afirmou pertencer. "Por que Filisa não se internou em tratamento psiquiátrico?" perguntou um colunista do Gay News de Seattle. "Por que Filisa não exigiu seus direitos civis?" Nesse caso, os aldeões raivosos não apenas perseguiram seu monstro até a saída da cidade, mas também a repreenderam por ser vulnerável às tochas. Filisa Vistima cometeu suicídio ou a comunidade queer de Seattle a matou? ${ }^{4}$

Eu quero reivindicar o poder sombrio de minha identidade monstruosa sem usálo como uma arma contra os outros nem ser ferida por ele. Direi da maneira mais direta possível: sou uma transexual e, portanto, sou um monstro. Assim como as palavras "sapatão", "bicha", "viado", "vadia" e "puta" foram reivindicadas, respectivamente, por lésbicas e gays, por minorias sexuais anti-assimilacionistas, por mulheres que buscam o prazer erótico, e por trabalhadoras da indústria do sexo, palavras como "criatura", "monstro" e "não natural" precisam ser resgatadas pelas pessoas transgêneras. Ao abraçá-las e aceitá-las, até mesmo amontoando essas palavras, podemos dissipar sua capacidade de nos ferir. Afinal, uma criatura na tradição dominante da cultura da Europa Ocidental nada mais é do que um ser criado, uma coisa produzida. A afronta que vocês, humanos, sentem ao serem chamados de "criatura" resulta da ameaça que o termo representa ao seu status de "senhores da criação," seres elevados acima da mera existência material. Como no caso de ser chamada de "it" $¥$ [5], ser chamada de "criatura" sugere a falta ou perda de uma pessoalidade superior. Eu não sinto vergonha, entretanto, em reconhecer minha relação igualitária com o Ser material não humano; tudo emerge da mesma matriz de possibilidades. "Monstro" é derivado do substantivo latino monstrum, "portento divino", ele próprio formado da raiz do verbo monere, "advertir." Passou a se referir a coisas vivas de forma ou estrutura anômala, ou a criaturas fabulosas como a esfinge, que eram compostas de partes notavelmente

‡ O pronome "it", em ingles, é usado para denotar objetos e animais, seres de sexo não especificado, situações ou ações indeterminadas. É usado onde a língua portuguesa muitas vezes exige a opção por "ele" ou "ela". [N.T.]

Dossiê Feminismos vitais - https://revistaecopos.eco.ufri.br/

ISSN 2175-8689 - v. 24, n. 1, 2021

DOI: 10.29146/ecopos.v24i1.27775 
incongruentes, porque os antigos consideravam o aparecimento de tais seres como um sinal de algum evento sobrenatural iminente. Monstros, como anjos, funcionavam como mensageiros e arautos do extraordinário. Eles serviam para anunciar uma revelação iminente, dizendo, com efeito: "Preste atenção; algo de profunda importância está acontecendo".

Escutai-me, criaturas. Eu que vivi em uma forma incompatível com meu desejo, eu cuja carne se tornou um conjunto de partes anatômicas incongruentes, eu que alcancei a semelhança de um corpo natural apenas por um processo não natural, ofereço-lhe este aviso: a Natureza com a qual você me atormenta é uma mentira. Não confie nela para protegê-lo do que eu represento, pois é uma fabricação que mascara a falta de fundamento do privilégio que você procura manter para si às minhas custas. Você é tão construída quanto eu; o mesmo útero anárquico deu à luz a nós duas. Te convoco a investigar sua natureza como eu fui compelida a confrontar a minha. Eu te desafio a arriscar a abjeção e florescer tão bem quanto eu. Ouça minhas palavras, e pode bem ser que você descubra as costuras e suturas em si mesmo.

\section{Crítica}

Em resposta à pergunta que ele coloca no título de seu recente ensaio, "O que é um monstro? (De acordo com Frankenstein)", Peter Brooks sugere que, seja o que for que um monstro possa ser, "também pode ser aquilo que foge à definição de gênero" (219). Brooks lê a história de Mary Shelley de um cientista que excede limites e sua criação problemática como uma dissidência precoce da tradição literária realista do século XIX, que ainda não havia, à época, alcançado a dominância enquanto forma narrativa. Ele entende que Frankenstein se desdobra textualmente por meio de uma estratégia narrativa gerada pela tensão entre uma epistemologia visualmente orientada, de um lado, e outra abordagem para conhecer a verdade dos corpos que privilegia a dimensão lingüística verbal, do outro (199-200). Conhecer por ver e conhecer por falar/escutar são atribuídos a gêneros específicos, respectivamente, como masculino e feminino no arcabouço crítico dentro da qual Brooks opera. Considerado neste contexto, 
o texto de Shelley é informado por - e critica do ponto de vista de uma mulher - a reordenação contemporânea do conhecimento realizada pelas reivindicações de verdade cada vez mais convincentes da ciência iluminista. 0 monstro problematiza o gênero em parte devido ao seu fracasso como sujeito viável no campo visual; embora seja referido como "ele", o monstro oferece assim uma resistência feminina, e potencialmente feminista, à definição por uma escopofilia falicizada. 0 monstro realiza essa resistência dominando a linguagem a fim de reivindicar uma posição como sujeito falante e realizar verbalmente a mesma subjetividade que lhe é negada no reino especular. ${ }^{5}$

A monstruosidade transexual, no entanto, junto com seu afeto, a fúria transgênera, nunca pode reivindicar um meio de resistência tão seguro por causa da incapacidade da linguagem de representar o movimento do sujeito transgênero ao longo do tempo entre posições de gênero estáveis em uma estrutura linguística. Nossa situação inverte efetivamente aquela encontrada pelo monstro de Frankenstein. Ao contrário do monstro, muitas vezes citamos com sucesso as normas visuais da cultura de incorporação de gênero. Essa citação torna-se uma resistência subversiva quando, por meio de um uso provisório da linguagem, declaramos verbalmente a não naturalidade de nossa reivindicação de posições de sujeito que, mesmo assim, ocupamos. ${ }^{6}$

A possibilidade de um monstro com vida e vontade própria é a principal fonte de horror para Frankenstein. 0 cientista assumiu seu projeto com um objetivo específico em mente - nada menos do que a intenção de submeter a natureza completamente ao seu poder. Ele encontra um meio de realizar seus desejos por meio da ciência moderna, cujos devotos, parece-lhe, "adquiriram poderes novos e quase ilimitados; eles podem comandar os trovões do céu, imitar o terremoto e até zombar do mundo invisível com suas sombras... Mais, muito mais, eu alcançarei”, pensou Frankenstein. "Serei o pioneiro de um novo caminho, explorarei poderes desconhecidos e revelarei ao mundo os mistérios mais profundos da criação" (Shelley 47). O fruto de seus esforços não é, entretanto, o que Frankenstein previa. 0 arrebatamento que ele esperava sentir no 
despertar de sua criatura transformou-se imediatamente em temor. "Eu vi os olhos amarelos e opacos da criatura se abrindo... Suas mandíbulas se abriram e ele murmurou alguns sons inarticulados, enquanto um sorriso enrugou suas bochechas. Ele pode ter falado, mas eu não ouvi; uma de suas mãos estava estendida, aparentemente para me deter, mas eu escapei" (Shelley 56,57). 0 monstro também escapa e se separa de seu criador por vários anos. Nesse tempo, ele aprende algo sobre sua situação no mundo e, em vez de abençoar seu criador, o monstro o amaldiçoa. 0 próprio sucesso do cientista de Mary Shelley em sua tarefa auto-nomeada, assim, paradoxalmente prova sua futilidade: em vez de demonstrar o poder de Frankenstein sobre a materialidade, o corpo recém-animado da criatura atesta ao fracasso de seu criador em atingir o domínio que buscava. Frankenstein não pode controlar a mente e os sentimentos do monstro que ele cria, que excede e refuta os propósitos do cientista.

Minha própria experiência como transexual é paralela à do monstro nesse aspecto. A consciência moldada pelo corpo transexual não é mais criação da ciência que refigura sua carne do que a mente do monstro é criação de Frankenstein. A agenda que produziu técnicas de redesignação hormonal e cirúrgica do sexo não é menos pretensiosa e nem mais nobre do que a de Frankenstein. Médicos heróicos ainda se esforçam para triunfar sobre a natureza. 0 discurso científico que produziu as técnicas de redesignação sexual é inseparável da busca da imortalidade por meio do aperfeiçoamento do corpo, da fantasia de domínio total por meio da transcendência de um limite absoluto e do desejo soberbo de criar a própria vida.7 Sua genealogia emerge de uma busca metafísica mais antiga que a ciência moderna, e suas políticas culturais estão alinhadas a uma tentativa profundamente conservadora de estabilizar a identidade de gênero a serviço da ordem heterosexual naturalizada.

Nada disso, no entanto, impede que corpos transexuais construídos medicamente sejam locais viáveis de subjetividade. Tampouco garante a adesão dos sujeitos assim incorporados à agenda que resultou em um meio transexual de incorporação. À medida que nos levantamos das mesas de operação do nosso renascimento, nós transexuais somos algo mais, e algo diferente, do que as criaturas que 
nossos criadores pretendiam que fossemos. Embora as técnicas médicas de redesignação sexual sejam capazes de fabricar corpos que satisfaçam os critérios visuais e morfológicos que geram naturalidade como seu efeito, o envolvimento com essas mesmas técnicas produz uma experiência subjetiva que desmente o efeito naturalista que a tecnologia biomédica pode alcançar. A incorporação transexual, como a incorporação do monstro, coloca seu sujeito numa relação inassimilável, antagônica e estranha ou queer com uma Natureza na qual, ainda assim, deve existir.

O monstro de Frankenstein articula sua situação não natural dentro do mundo natural com muito mais sofisticação no romance de Shelley do que poderia ser esperado por aqueles que estão familiarizados apenas com a versão interpretada por Boris Karloff nos filmes clássicos de James Whale da década de 1930. 0 crítico de cinema Vito Russo sugere que a interpretação de Whale sobre o monstro foi influenciada pelo fato de o diretor ser um homem gay dentro do armário na época em que fez seus filmes de Frankenstein. 0 pathos que ele transmitiu a seu monstro derivou da experiência de sua própria identidade sexual oculta. ${ }^{8}$ Monstruoso e não natural aos olhos do mundo, mas buscando apenas o amor de sua própria espécie e a aceitação da sociedade humana, a criatura de Whale exterioriza e torna visível a solidão e alienação que o armário pode gerar. Mas este não é o monstro que fala com tanta força de minha própria situação como ser abertamente transexual. Em vez disso, emulo o monstro literário de Mary Shelley, que é astuto, ágil, forte e eloquente.

No romance, a criatura foge do laboratório de Frankenstein e se esconde na solidão dos Alpes, onde, por meio da observação furtiva das pessoas que encontra, gradualmente adquire um conhecimento da linguagem, da literatura e das convenções da sociedade europeia. No início, ele sabe pouco sobre sua própria condição. "Eu nunca tinha visto um ser parecido comigo, ou que afirmasse qualquer relação comigo", observa o monstro. "O que isso significa? Quem sou eu? 0 que eu fui? De onde eu vim? Qual seria o meu destino? Essas questões se repetiam continuamente, mas eu não conseguia resolvê-las" (Shelley 116, 130). Então, no bolso da jaqueta que levou enquanto fugia do laboratório, o monstro encontra o diário de Victor Frankenstein e aprende os detalhes

Dossiê Feminismos vitais - https://revistaecopos.eco.ufri.br/

ISSN 2175-8689 - v. 24, n. 1, 2021

DOI: 10.29146/ecopos.v24i1.27775 
de sua criação. "Eu fiquei enjoado enquanto lia", diz o monstro. "O aumento do conhecimento só me mostrou como eu era um pária miserável” (Shelley 124,125).

Ao aprender sua história e experimentar a rejeição de todos a quem procurou como companhia, a vida da criatura dá uma virada sombria. "Meus sentimentos eram de fúria e vingança", declara o monstro. "Eu, como o arqui-demônio, carregava um inferno dentro de mim" (130). Teria ficado feliz em destruir toda a Natureza, mas decide, finalmente, pelo plano mais conveniente de assassinar sistematicamente todos aqueles que Victor Frankenstein ama. Assim que Frankenstein percebe que sua própria criação abandonada é responsável pela morte de seus entes mais queridos, ele se retira em remorso para uma aldeia nas montanhas acima de sua Genebra natal para refletir sobre sua cumplicidade nos crimes que o monstro cometeu. Ao caminhar pelas geleiras à sombra do Mont Blanc, acima da aldeia de Chamonix, Frankenstein avista uma figura familiar se aproximando dele através do gelo. Claro, é o monstro que exige uma audiência com seu criador. Frankenstein concorda, e os dois se retiram juntos para a cabana de um montanhista. Lá, em um monólogo que ocupa quase um quarto do romance, o monstro conta a Frankenstein a história de sua criação de seu próprio ponto de vista, explicando-lhe como ficou tão enfurecido.

Estas são minhas palavras para Victor Frankenstein, acima da aldeia de Chamonix. Como o monstro, eu poderia falar sobre minhas primeiras memórias e como me dei conta de minha diferença em relação a todos ao meu redor. Posso descrever como adquiri uma identidade monstruosa ao assumir o rótulo de "transexual" para nomear partes de mim que não poderia explicar de outra forma. Eu também descobri os diários dos homens que fizeram meu corpo e que fizeram os corpos de criaturas como eu desde os anos 1930. Eu conheço em detalhes íntimos a história desta recente intervenção médica na realização da subjetividade transgênera; a ciência busca conter e colonizar a ameaça radical representada por uma particular estratégia transgênera de resistência à coercitividade do gênero: a alteração física dos genitais. ${ }^{9}$ Eu vivo diariamente com as consequências da definição da minha identidade pela medicina como um distúrbio emocional. Por meio do filtro dessa patologização oficial, os sons que

Dossiê Feminismos vitais - https://revistaecopos.eco.ufri.br/

ISSN 2175-8689-v. 24, n. 1, 2021

DOI: 10.29146/ecopos.v24i1.27775 
saem de minha boca podem ser sumariamente descartados como o delírio confuso de uma mente doente.

Como o monstro, quanto mais tempo eu vivo nessas condições, mais fúria eu guardo. A fúria me colore ao entrar pelos poros da minha pele, me encharcando até se tornar o sangue que corre pelo meu coração palpitante. É uma fúria gerada pela necessidade de existir em circunstancias externas que trabalham contra minha sobrevivência. Mas há ainda outra fúria dentro de mim.

\section{Diário (18 de Fevereiro de 1993)}

Kim estava sentada entre minhas pernas abertas, de costas para mim, o cóccix na beirada da mesa. Sua mão esquerda agarrou minha coxa com tanta força que os hematomas ainda estão lá uma semana depois. Suando e berrando, ela empurrou uma última vez e o bebê finalmente nasceu. Pelas costas da minha amante, contra a pele da minha própria barriga, senti uma criança sair do corpo de outra mulher e entrar no mundo. As mãos de estranhos a arrebataram para sugar o mecônio verde pegajoso de suas vias respiratórias. "É uma menina", alguém disse. Paul, eu acho. Por que, naquele momento, uma confusão de sentimentos sombrios e espontâneos emergiram sem palavras de algum canto silencioso do fundo da minha mente? Este momento de milagres não era a hora de lidar com eles. Eu os empurrei de volta, sabendo que eles eram muito fortes para evitar por muito tempo.

Depois de três dias, estávamos todos exaustos, ligeiramente desapontados que complicações tinham nos forçado a ir para o Kaiser em vez de ter o parto em casa. Me pergunto o que os funcionários do hospital pensaram de nossa pequena tribo que invadiu a sala de parto: Stephanie, a parteira; Paul, o pai do bebê; Gwen, irmã da Kim; meu filho Wilson e eu; e as duas outras mulheres que constituem nossa família, Anne e Heather. E, claro, Kim e o bebê. Ela a chamou de Denali, em homenagem à montanha no Alasca. Eu não acho que o pessoal médico tinha a menor ideia de como todos nós nos considerávamos parentes. Quando o trabalho de parto começou, nós nos revezamos, alternando entre vários papéis de apoio, mas à medida que a provação avançava, 
estabelecemos um padrão mais estável. Eu me descobri atuando como coach de parto. Hora após hora, através de dezenas de séries de contrações, concentrei tudo em Kim, ajudando-a a manter o controle de suas emoções enquanto ela se entregava a esse processo inexorável, segurando seus olhos com os meus para evitar que a dor a expulsasse de seu corpo, respirando cada respiração com ela, sendo uma companheira. Eu participei, passo a cada vez mais íntimo passo, da transformação ritual da consciência em torno do nascimento de sua filha. Os rituais de nascimento trabalham para preparar o eu para uma abertura profunda, uma abertura tão psíquica quanto corpórea. 0 corpo de Kim levou esse processo ritual a uma resolução dramática para ela, culminando em uma experiência catártica e visceral. Mas meu corpo me deixou pendurada. Eu havia feito uma viagem até o ponto em que minha companheira precisava seguir sozinha e eu precisava terminar minha viagem por conta própria. Para concluir o ritual de nascimento do qual participei, precisava mover algo em mim tão profundo quanto toda uma vida humana.

Eu flutuei do hospital para casa, cheia de uma energia vital que não descarregava. Não parei quieta até ficar sozinha: minha ex tinha vindo buscar Wilson; Kim e Denali ainda estavam no hospital com Paul; Stephanie foi embora e todos os outros saíram para uma caminhada muito necessária. Finalmente, na solidão de minha casa, explodi como um saco de papel molhado e deixei derramar o conteúdo emocional de minha vida pelas mãos, que coloquei como uma peneira no rosto. Durante dias, enquanto acompanhava minha companheira em sua jornada, eu estava me abrindo progressivamente, me preparando para deixar ir embora aquilo que fosse de mais profundo dentro de mim. Agora tudo em mim fluía para fora, subindo de dentro e para fora pela minha garganta, minha boca, porque essas coisas nunca poderiam passar entre os lábios da minha boceta. Eu sabia que a escuridão que vislumbrara antes iria ressurgir, mas eu tinha vastos oceanos de sentimento para experimentar antes que ela surgisse novamente.

A simples alegria na presença da nova vida borbulhou para fora primeiro, onda após onda dela. Eu estava tão incrivelmente feliz. Eu estava tão apaixonada por Kim, 
tinha tanta admiração por sua força e coragem. Senti orgulho e animação pela família queer que estávamos construindo com Wilson, Anne, Heather, Denali e todos os bebês que se seguissem. Todos nós experimentamos uma possibilidade empolgante na vida comunitária e nesses laços criadores e parentescos acordados para os quais não temos nomes adequados. Brincamos sobre sermos pioneiros numa fronteira reversa: aventurarmo-nos ao coração da própria civilização para resgatar a reprodução biológica do heterossexismo e liberá-la para nossos próprios usos. Somos ferozes; num mundo de "valores familiares tradicionais", precisamos ser.

Às vezes, porém, ainda lamento a passagem de modos mais antigos e familiares. Não faz muito tempo que minha ex e eu nos casamos, mulher e homem. Aquele amor fora genuíno e o luto por sua perda real. Sempre quis intimidade com mulheres mais do que com homens, e esse desejo sempre me pareceu queer. Ela precisava que tivesse uma aparência hétero. A forma da minha carne era uma barreira que me alienava do meu desejo. Como um corpo sem boca, eu estava morrendo de fome no meio da abundância. Eu não me permitiria morrer de fome, mesmo que o que fosse necessário para me abrir para uma conexão profunda cortasse as conexões mais profundas que eu de fato tinha. Então, abandonei uma vida e construí esta nova. 0 fato de que ela e eu começamos a nos dar bem novamente, depois de tanta disputa entre nós, torna a amargura de nossa separação um tanto doce. No dia do nascimento, essa perda passada estava presente mesmo em sua recuperação parcial; vista ao lado da plenitude recém-descoberta em minha vida, ela evocou uma tristeza pungente e esperançosa que me inundou.

Frustração e raiva logo jorraram em abundância. Apesar de tudo que eu havia conquistado, minha identidade ainda parecia tão tênue. Cada circunstância da vida parecia conspirar contra mim em um ato vasto e composto de invalidação e apagamento. No corpo com que nasci, eu fora invisível como a pessoa que me considerava ser; eu fora invisível como queer enquanto a forma do meu corpo fazia meus desejos parecerem héteros. Agora, como sapatona, sou invisível entre as mulheres; como transexual, sou invisível entre as lésbicas. Como companheira de uma nova mãe, muitas vezes sou invisível como transexual, mulher e lésbica - perdi a conta 
dos amigos e conhecidos nos últimos nove meses que me perguntaram se eu era o pai. Isso mostra dramaticamente o quanto eles simplesmente não entendem o que estou fazendo com meu corpo. 0 alto preço de qualquer auto-representação visível e inteligível que eu alcancei torna a experiência contínua da invisibilidade enlouquecedoramente difícil de suportar.

As suposições coletivas da ordem naturalizada logo me inundaram. A natureza exerce uma opressão tão hegemônica. De repente, me senti perdida e com medo, sozinha e confusa. Como aquele menininho mórmon de Oklahoma que eu já fui um dia cresceu e se tornou uma sapatona transexual vestida de couro em San Francisco com um Ph.D. de Berkeley? Manter meu rumo em uma viagem tão longa e estranha parecia uma proposta ridícula. A minha casa, há tanto deixada para trás, estava tão longe que se foi para sempre, e não havia lugar para descansar. Atingida por fortes emoções, um pouco atordoada, senti as paredes internas que me protegem se dissolverem para me deixar vulnerável a tudo o que poderia me fazer mal. Eu chorei e me abandonei ao desespero abjeto sobre o que o gênero tinha feito comigo.

Tudo é uma merda tão grande que nem dá para reconhecer. Dói demais continuar. Cheguei hoje o mais perto que chegarei a dar à luz - literalmente. Meu corpo não pode fazer isso; não consigo nem sangrar sem um ferimento, e ainda assim afirmo ser mulher. Como? Por que sempre me senti assim? Eu sou uma aberração maldita. Nunca poderei ser mulher como as outras mulheres, mas nunca poderia ser homem. Talvez realmente não haja lugar para mim em toda a criação. Estou tão cansada desse movimento incessante. Eu faço guerra com a natureza. Estou alienada de Ser. Eu sou uma deformidade automutilada, uma pervertida, uma mutante, presa em carne monstruosa. Deus, eu nunca quis ficar presa novamente. Eu me destruí. Estou caindo na escuridão, estou caindo aos pedaços.

Eu entro no domínio dos meus sonhos. Estou debaixo d'água, nadando para cima. Está escuro. Eu vejo uma luz tremeluzente acima de mim. Eu rompo o plano da superfície d'água com meus pulmões estourando. Eu sugo o ar - e encontro apenas mais água. Meus pulmões estão cheios d'água. Por dentro e por fora, estou cercado por ela. Por que não 
estou morta se não há diferença entre mim e onde me encontro. Há outra superfície acima de mim e nado freneticamente em sua direção. Eu vejo uma luz tremeluzente. Eu quebro o plano da superfície da água uma e outra e outra vez. Essa água me aniquila. Eu não posso ser, e ainda - uma impossibilidade excruciante - eu sou. Farei qualquer coisa para não estar aqui.

Eu vou nadar para sempre.

Eu vou morrer para a eternidade.

Eu vou aprender a respirar água.

Eu vou me transformar em água.

Se eu não posso mudar minha situação vou me mudar.

Nesse ato de transformação mágica.

Eu me reconheço novamente.

Sou movimento sem chão e sem limite.

Sou um fluxo furioso.

Sou uma com a escuridão e o molhado.

E estou furiosa.

Aqui finalmente está o caos que mantive à distância.

Aqui finalmente está minha força.

Eu não sou a água-

eu sou a onda,

e fúria

é a força que me move.

Fúria

Me devolve meu corpo

como seu próprio meio fluido

Fúria

soca um buraco n'água

em torno do qual eu coalesço

para permitir que o fluxo passe por mim.

Fúria Me constitui na minha forma primal

Joga minha cabeça para trás

puxa meus lábios de volta sobre meus dentes

Dossiê Feminismos vitais - https://revistaecopos.eco.ufri.br/

ISSN 2175-8689 - v. 24, n. 1, 2021

DOI: 10.29146/ecopos.v24i1.27775 
abre minha garganta

e me levanta para uivar:

: e nenhum som

dilui

a qualidade pura da minha fúria.

Nenhum som

existe

neste lugar sem linguagem

minha fúria é um delírio silencioso.

Fúria

Me joga de volta finalmente

à realidade mundana

nessa carne transfigurada

que me alinha com o poder do meu Ser.

Ao fazer nascer minha fúria,

minha fúria me fez renascer.

\section{Teoria}

Uma disjunção formal parece particularmente apropriada neste momento porque o afeto que procuro examinar criticamente, o que chamei de "fúria transgênera", emerge dos interstícios das práticas discursivas e do colapso de categorias genéricas. A própria fúria é gerada pela situação do sujeito num campo regido pela relação instável, mas indissolúvel, entre linguagem e materialidade; uma situação em que a linguagem organiza e traz à significação matéria que simultaneamente escapa à representação definitiva e exige sua própria rearticulação perpétua em termos simbólicos. Nesse campo dinâmico, o sujeito deve policiar constantemente a fronteira construída por sua própria fundação, a fim de manter as ficções de "dentro" e "fora" contra um regime de significação/materialização cuja instabilidade intrínseca produz a ruptura das fronteiras subjetivas como uma de suas características regulares. 0 afeto da fúria, como procuro defini-lo, está localizado na margem da subjetividade e no limite da significação. Origina-se no reconhecimento do fato de que a "exterioridade" de uma materialidade que perpetuamente viola o repúdio do espaço subjetivo dentro de uma 
ordem simbólica também está necessariamente "dentro" do sujeito como fundamento para a materialização de seu corpo e a formação de seu ego corporal.

Essa fúria primária torna-se fúria especificamente transgênera quando ocorre a incapacidade de precludir o sujeito, devido à falha em satisfazer as normas de incorporação de gênero. A fúria transgênera é a experiência subjetiva de ser compelida a transgredir o que Judith Butler chamou de esquemas regulatórios altamente generificados que determinam a viabilidade dos corpos, de ser compelida a entrar num "domínio de corpos abjetos, um campo de deformação" que em sua inabitabilidade abrange e constitui o reino da subjetividade legítima (16). A fúria transgênera é uma fúria queer, uma resposta emocional às condições em que se torna imperativo assumir, para o bem da própria sobrevivência continuada como sujeito, um conjunto de práticas que precipita a própria exclusão de uma ordem naturalizada de existência que busca manter-se como única base possível para ser sujeito. No entanto, ao mobilizar identidades de gênero e torná-las provisórias, abertas ao desenvolvimento e ocupação estratégica, essa fúria possibilita o estabelecimento de sujeitos em novos modos de existência, regulados por diferentes códigos de inteligibilidade. A fúria transgênera fornece um meio de desidentificação com posições de sujeito atribuídas compulsoriamente. Torna possível a transição de uma posição de sujeito generificada para outra, ao usar a impossibilidade de preclusão subjetiva completa para organizar uma força externa como um impulso interno e vice-versa. Por meio da operação da fúria, o próprio estigma se torna a fonte de poder transformador. ${ }^{10}$

Quero parar e teorizar neste momento particular do texto porque no momento vivido em que fui jogada de volta de um estado de abjeção após o nascimento da filha da minha amante, comecei imediatamente a contar a mim mesma uma história para explicar minha experiência. Comecei a teorizar, usando todas as ferramentas conceituais que minha formação colocou à minha disposição. Outras histórias verdadeiras desses eventos poderiam, sem dúvida, ser contadas, mas ao voltar eu sabia com certeza o que acendeu o estopim da minha fúria na sala de parto do hospital. Foi a não consensualidade da atribuição de gênero do bebê. Veja, disse a mim mesma, 
limpando a meleca do rosto com a manga de uma camisa, os corpos só se tornam significativos por meio de algum modo cultural e historicamente específico de apreender sua fisicalidade que transforma a carne em um artefato útil. A generificação é o passo inicial dessa transformação, indissociável do processo de formação de uma identidade por meio da qual somos adequadas a um sistema de trocas em uma economia heterossexual. A autoridade se agarra a qualidades materiais específicas da carne, particularmente os genitais, como indicação externa do potencial reprodutivo futuro, constrói essa carne como um signo e o lê para enculturar o corpo. A atribuição de gênero é compulsória; codifica e posiciona nossos corpos de maneiras que nos afetam materialmente, mas não escolhemos nem nossas marcas nem os significados que carregam. ${ }^{11}$ Esse foi o ato realizado entre o início e o fim daquela curta frase na sala de parto: "É uma menina." Esse foi o ato que me lembrou de toda a angústia de minhas próprias lutas com o gênero. Mas esse também foi o ato que impôs minha cumplicidade na generificação não consensual de outra pessoa. Uma violência de atribuição de gênero é a condição fundadora da subjetividade humana; ter um gênero é a tatuagem tribal que torna a pessoalidade da pessoa conhecível. Fiquei por um momento entre as dores de duas violações, a marca do gênero e a impossibilidade de viver em sua ausência. Poderia dizer qual era pior? Ou poderia apenas dizer a qual eu achava mais possível sobreviver?

Como encontrar-se prostrada e impotente na presença da Lei do Pai não produziria uma fúria inexprimível? Que diferença faz se o pai, neste caso, era um anarquista viado punk, tatuado, com piercing e cabelos roxos que ajudou sua amiga sapatona a engravidar? A linguagem falogocêntrica, não seu falante específico, é o bisturi que define nossa carne. Eu desafio essa Lei em minha recusa em sujeitar-me ao seu decreto original do meu gênero. Embora eu não possa escapar de seu poder, posso me mover através de seu meio. Talvez, se eu me mover furiosa o suficiente, consiga deformá-lo ao passar, para deixar um traço de minha fúria. Posso abraçá-lo com toda a força para me renomear, declarar minha transexualidade e assim obter acesso aos meios de minha reinscrição legível. Embora talvez não seja eu que segure o buril, posso me mover por baixo dele para meus próprios profundos prazeres autossustentados.

Dossiê Feminismos vitais - https://revistaecopos.eco.ufri.br/

ISSN 2175-8689-v. 24, n. 1, 2021

DOI: 10.29146/ecopos.v24i1.27775 
Ir de encontro com o corpo transexual, apreender uma consciência transgênera que se articula, é arriscar uma revelação do caráter construído da ordem natural. Confrontar as implicações disso pode evocar toda a violação, perda e separação infligidas pelo processo generificador que sustenta a ilusão de naturalidade. Meu corpo transexual literaliza essa violência abstrata. Como portadores desta notícia inquietante, nós transexuais muitas vezes sofremos pela dor dos outros, mas não suportamos de bom grado a fúria dos outros dirigida contra nós. E nós temos algo mais a dizer, se apenas ouvirem os monstros: a possibilidade de agência e ação significativas existe, mesmo dentro de campos de dominação que ocasionam o estupro cultural universal de toda a carne. Estejam conscientes, no entanto, que assumir essa tarefa significa ser refeita no processo.

Ao falar como um monstro com minha voz pessoal, ao usar as imagens sombrias e aquosas do Romantismo e, ocasionalmente, caindo em suas cadências taciturnas e posturas grandiosas, eu emprego as mesmas técnicas literárias que Mary Shelley usou para despertar simpatia pela criação de seu cientista. Como aquela criatura, eu afirmo meu valor como monstro, apesar das condições que minha monstruosidade exige que eu enfrente, e redefino uma vida que valha a pena viver. Eu já fiz as perguntas miltônicas que Shelley coloca na epígrafe de seu romance: "Pedi eu, ó meu criador, que do barro me fizesses homem? Pedi para que me arrancasses das trevas?" A uma só voz, seu monstro e eu respondemos "não" sem nos rebaixarmos, pois fizemos o árduo trabalho de nos constituirmos em nossos próprios termos, contra a ordem natural. Embora renunciemos ao privilégio da naturalidade, não somos dissuadidos, pois nos aliamos ao caos e à escuridão dos quais a própria Natureza derrama. ${ }^{12}$

Se esse é seu caminho, como é o meu, deixe-me oferecer qualquer consolo que você possa encontrar nesta bênção monstruosa: Que você descubra o poder vivificante das trevas dentro de você. Que nutra sua fúria. Que sua fúria informe suas ações, e que suas ações lhe transformem enquanto você luta para transformar seu mundo.

\section{Referências bibliográficas:}

Benjamin, Harry. The Transsexual Phenomenon. New York: Julian, 1966.

Dossiê Feminismos vitais - https://revistaecopos.eco.ufri.br/

ISSN 2175-8689 - v. 24, n. 1, 2021

DOI: 10.29146/ecopos.v24i1.27775 
Billings, Dwight B.; Urban, Thomas. "The Socio-Medical Construction of Transsexualism: An Interpretation and Critique." Social Problems 29 (1981): 266-82.

Bloom, Harold. "Afterword." Frankenstein, or The Modern Prometheus. New York: Signet/NAL, 1965, p.212-23. Reedição de: "Frankenstein, or The New Prometheus." Partisan Review 32 (1965): 611-18.

Brooks, Peter. Body Work: Objects of Desire in Modern Narrative. Cambridge, MA: Harvard University Press, 1993.

Butler, Judith. Bodies That Matter: On the Discursive Limits of "Sex." New York: Routledge, 1993.

Daly, Mary. Gyn/Ecology: The Metaethics of Radical Feminism. Boston: Beacon, 1978.

Echols, Alice. Daring to Be Bad: Radical Feminism in America, 1967-1975. Minneapolis: University of Minnesota Press, 1989.

Gilbert, Sandra; Gubar, Susan. “Horror's Twin: Mary Shelley's Monstrous Eve.” The Madwoman in the Attic. New Haven: Yale University Press, 1979, p.213-47.

Green, Richard; Money, John (orgs.). Transsexualism and Sex Reassignment. Baltimore: Johns Hopkins University Press, 1969.

Guillaumin, Colette. 'Race and Nature: The System of Marks.', Feminist Studies 8 (1988): 25-44.

Homans, Margaret. "Bearing Demons: Frankenstein's Circumvention of the Maternal." Bearing the Word. Chicago: Chicago University Press, 1986, p. 100-119.

Irvine, Janice. Disorders of Desire: Sex and Gender in Modern American Sexologv. Philadelphia: Temple University Press, 1990.

Jacobus, Mary. "Is There a Woman in this Text?" Reading Woman: Essays in Feminist Criticism. New York: Columbia University Press, 1986, p. 83-109.

Kahler, Frederic. “Does Filisa Blame Seattle?" Editorial. Bay Times [San Francisco] 3 jun. 1993: 23.

Kessler, Suzanne J.; McKenna, Wendy. Gender: An Ethnomethodological Approach. Chicago: University of Chicago Press, 1985.

Laqueur, Thomas. Making Sex: Body and Gender from the Greeks to Freud. Cambridge, MA: Harvard University Press, 1990.

Meyer, Morris. "I Dream of Jeannie: Transsexual Striptease as Scientific Display." The Drama Review. 35.1 (1991): 25-42.

Mikuteit, Debbie. Letter. Coming Up! Fev. 1986: 3-4.

Nanda, Serena. Neither Man Nor Woman: The Hijras of' India. Belmont, CA: Wadsworth, 1990.

O’Hartigan, Margaret D. “I Accuse.” Bay Times [San Francisco] 20 May 1993: 11.

Raymond, Janice G. The Transsexual Empire: The Making of the She-Male. Boston: Beacon, 1979.

Roscoe, Will. "Priests of the Goddess: Gender Transgression in the Ancient World." American Historical Association Meeting. 9 January 1994. San Francisco.

Dossiê Feminismos vitais - https://revistaecopos.eco.ufri.br/

ISSN 2175-8689-v. 24, n. 1, 2021

DOI: 10.29146/ecopos.v24i1.27775 
Rubin, Gayle. "The Traffic in Women: Notes on the 'Political Economy' of Sex." In: Rayna R. Reiter (org.). Toward an Anthropology of Women. New York: Monthly Review Press, 1975, p. 157-210.

Russo, Vito. The Celluloid Closet: Homosexuality in the Movies. New York: Harper and Row, 1981. Shapiro, Judith. "Transsexualism: Reflections on the Persistence of Gender and the Mutability of Sex." In: Julia Epstein e Kristina Straub (orgs.). Body Guards: The Cultural Politics of Gender Ambiguity. New York: Routledge, 1991, p.248-79.

Shelley, Mary. Frankenstein, or The Modern Prometheus. New York: Signet/NAL, 1965 [1817].

Stoller, Robert. Sex and Gender, Vol. 1. New York: Science House, 1968.

Stoller, Robert. The Transexual Experiment: Sex and Gender, Vol.2. London: Hogarth, 1975.

Stone, Sandy. "The Empire Strikes Back: A Posttranssexual Manifesto." In: Julia Epstein e Kristina Straub (orgs.). Bodv Guards: The Cultural Politics of Gender Ambiguity. New York: Routledge, 1991, p. 280-304.

Williams, Walter. The Spirit and the Flesh: Sexual Diversitv in American Indian Culture. Boston: Beacon, 1986.

Wittig, Monique. "The Mark of Gender." The Straight Mind and Other Essays. Boston: Beacon,1992, p. 70-89.

\footnotetext{
${ }^{1}$ Embora este comentário tenha a intenção de ser uma rejeição desdenhosa vinda de um monstro, ainda assim, ele alude a um debate substancial sobre o status das práticas e identidades trans no feminismo lésbico. H.S. Rubin, em uma tese de sociologia em andamento na Brandeis University, defende que o acentuado aumento demográfico na população de transexuais que fizeram transição do feminino para o masculino durante os anos 1970 e 1980 está diretamente relacionado à ascensão dentro do lesbianismo de um "feminismo cultural", que menosprezou e marginalizou práticas que sugerissem um modelo de "inversão de gênero" não liberado de homossexualidade - especialmente os papéis de butch-femme associados à cultura lésbica dos bares da classe trabalhadora. Assim, o feminismo cultural consolidou uma aliança lésbico-feminista com o feminismo heterossexual com base na condição de classe média, ao capitular às ideologias dominantes de gênero. Eu acrescentaria que a mesma supressão de aspectos transgêneros da prática lésbica simultaneamente levantou o fantasma de lésbicas transexuais masculinopara-feminino, como uma ameaça particular à estabilidade e pureza da identidade lésbica-feminista nãotransexual. Veja Echols para o contexto mais amplo deste debate, e Raymond para o exemplo mais veemente da posição anti-transgênero.

20 significado atual do termo "transgênero" é motivo de alguma controvérsia. A palavra foi originalmente cunhada como substantivo na década de 1970 por pessoas que resistiam à categorização como travestis ou transexuais e que usavam o termo para descrever sua própria identidade. Ao contrário das pessoas transexuais, mas como travestis, as pessoas transgêneras não buscam a alteração cirúrgica de seus corpos, mas habitualmente usam roupas que representam um gênero diferente daquele que lhes foi designado no nascimento. Ao contrário das travestis, mas como transexuais, no entanto, os transgêneros não alteram a codificação vestimentar de seu gênero apenas episodicamente ou principalmente para gratificação sexual; eles e elas expressam consistente e publicamente um compromisso contínuo com as identidades de gênero que afirmam, por meio das mesmas estratégias de representação visual usadas por outros e outras para significar esse gênero. A lógica subjacente a esta terminologia reflete a tendência generalizada de interpretar "gênero" como a manifestação sociocultural de um "sexo" material. Assim, enquanto pessoas transexuais expressam suas identidades por meio de uma mudança de incorporação, os
}

Dossiê Feminismos vitais - https://revistaecopos.eco.ufri.br/

ISSN 2175-8689-v. 24, n. 1, 2021

DOI: 10.29146/ecopos.v24i1.27775 
transgêneros o fazem por meio de uma mudança não-corpórea na expressão pública de gênero que, todavia, é mais complexa do que uma simples troca de roupas.

Este ensaio usa "transgênero" em um sentido mais recente, porém, do que o original. Ou seja, eu o uso aqui como um termo guarda-chuva que se refere a todas as identidades ou práticas que cruzam, atravessam, se movem entre, ou de outra forma queerificam as fronteiras socialmente construídas de sexo/gênero. 0 termo inclui, mas não se limita à, transexualidade, travestismo heterossexual, drag gay, lesbianismo butch e identidades não europeias como o berdache nativo americano ou a hijra indiana. Como "queer", "transgênero" também pode ser usado como verbo ou adjetivo. Neste ensaio, a transexualidade é considerada uma prática/identidade transgênero cultural e historicamente específica, por meio da qual um sujeito transgênero entra em um relacionamento com instituições médicas, psicoterapêuticas e jurídicas a fim de obter acesso a certas tecnologias hormonais e cirúrgicas para encenar-se e incorporar-se.

${ }^{3}$ Mikuteit 3-4, editado para brevidade e clareza.

${ }^{4} 0$ parágrafo anterior baseia-se muito e, às vezes, parafraseia 0’Hartigan e Kahler.

5 Veja Laqueur 1-7, para uma breve discussão do efeito do Iluminismo nas construções de gênero. As interpretações feministas de Frankenstein às quais Brooks responde incluem Gilbert e Gubar, Jacobus, e Homans.

${ }^{6} \mathrm{~A}$ fala abertamente transexual similarmente subverte a lógica por trás de uma observação de Bloom, 218, de que "um 'monstro' belo, ou mesmo um monstro passável, não teria sido um monstro."

7 Billings e Urban, 269, documentam especialmente bem a atitude médica em relação à cirurgia transexual como uma atitude de domínio técnico do corpo; Irvine, 259, sugere um encaixe da transexualidade no desenvolvimento da sexologia científica, embora seja aconselhável cautela para não aceitar sem crítica a interpretação da experiência transexual que ela apresenta nesse capítulo. Meyer, apesar de alguns comentários finais extremamente transfóbicos, oferece um bom relato da medicalização das identidades trans; para uma perspectiva transexual sobre a agenda científica por trás das técnicas de redesignação de sexo, consulte Stone, especialmente a seção intitulada "Toda a realidade na cultura no capitalismo tardio deseja se tornar uma imagem de sua própria segurança", (280-304).

8 Russo 49-50: "Paralelos homossexuais em Frankenstein (1931) e Noiva de Frankenstein (1935) surgiram de uma visão que ambos os filmes tinham do monstro como uma figura anti-social da mesma forma que os gays eram 'coisas' que não deveriam ter acontecido. Em ambos os filmes, a homossexualidade do diretor James Whale pode ter sido uma força na visão".

${ }^{9} \mathrm{Na}$ ausência de uma história crítica confiável da transexualidade, é melhor recorrer aos próprios relatos médicos de referência: ver especialmente Benjamin, Green e Money, e Stoller. Para visões gerais da variação transcultural na institucionalização do sexo/gênero, consulte Williams, "Social Constructions / Essential Characters: A Cross-Cultural Viewpoint," 252-76; Shapiro 262-68. Para relatos de institucionalizações específicas de práticas transgêneras que empregam alteração cirúrgica dos órgãos genitais, consulte Nanda; Roscoe. Leitores aventureiros e curiosos sobre as práticas contemporâneas de alteração genital não-transexuais podem entrar em contato com E.N.I.G.M.A. (Erotic Neoprimitive International Genital Modification Association), SASE para LaFarge-werks, 2329 N. Leavitt, Chicago, IL 60647.

10 Veja Butler, "Introdução", 4 e passim.

${ }^{11}$ Um grande volume de estudos informa essas observações: Gayle Rubin fornece um ponto de partida produtivo para o desenvolvimento não apenas de uma economia política do sexo, mas da subjetividade generificada; sobre recrutamento e atribuição de gênero, consulte Kessler e McKenna; sobre gênero como sistema de marcas que naturaliza grupos sociológicos a partir de semelhanças materiais supostamente compartilhadas, fui influenciada por algumas ideias sobre raça em Guillaumin e por Wittig.

${ }^{12}$ Embora eu queira dizer "caos" aqui em seu sentido geral, é interessante especular sobre a potencial aplicação da teoria científica do caos para modelar a emergência de estruturas estáveis de identidades de gênero a partir da matriz instável de atributos materiais, e sobre a produção de uma proliferação de identidades de gênero a partir de um conjunto relativamente simples de procedimentos de generificação.

Dossiê Feminismos vitais - https://revistaecopos.eco.ufri.br/

ISSN 2175-8689 - v. 24, n. 1, 2021

DOI: 10.29146/ecopos.v24i1.27775 